\title{
Development of nanosilver-coated geopolymer beads (AgGP) from fly ash and baluko shells for antimicrobial applications
}

\author{
Kimmie Dela Cerna ${ }^{1}$, Jose Isagani Janairo $^{2}$, and Michael Angelo Promentilla ${ }^{1}$ \\ ${ }^{1}$ Department of Chemical Engineering, Gokongwei College of Engineering, De La Salle University, 2401 Taft Avenue, \\ Manila 1004, Philippines \\ ${ }^{2}$ Department of Biology, College of Science, De La Salle University, 2401 Taft Avenue, Manila 1004, Philippines
}

\begin{abstract}
Geopolymers are a class of materials formed from treating alumina $\left(\mathrm{Al}_{2} \mathrm{O}_{3}\right)$ and silica $\left(\mathrm{SiO}_{2}\right)$ containing materials with an alkali activator. They are most notable for being environmentally-friendly substitutes to Ordinary Portland Cement; however, recent findings have shown that they may have potential as support matrices for antimicrobial agents such as nanosilver, particularly with the addition of foaming agents and setting time accelerators. In this study, nanosilver-coated geopolymer beads (AgGP) were made from fly ash (FA), calcined Baluko shells or pen shells (BS), and hydrogen peroxide (H). Addition of BS and $\mathrm{H}$ reduces the setting time and increases the porosity of the geopolymer beads. The beads were then dipped in $\mathrm{AgNO}_{3}$ and $\mathrm{NaBH} 4$ respectively to provide the nanosilver coating. When immersed in water, a controlled release of silver ions leaches out from the beads, neutralizing any bacteria in the water. It was found that the AgGP removed as much as $99.96 \%$ of the $E$. coli in a suspension originally at $105 \mathrm{CFU} / \mathrm{mL}$.
\end{abstract}

\section{Introduction}

Since the discovery of geopolymer chemistry in the 1970s, geopolymers have earned a reputation as a promising material. They have comparable compressive and flexural strengths with traditional cements, but have exceptional fire and acid attack resistance as well as a lower embodied $\mathrm{CO}_{2}$ footprint. They are formed by treating raw materials containing amorphous alumina $\left(\mathrm{Al}_{2} \mathrm{O}_{3}\right)$ and silica $\left(\mathrm{SiO}_{2}\right)$ with an alkali activator - typically a mixture of WGS and concentrated $\mathrm{NaOH}[\mathbf{1}]$.

Geopolymers are also sustainable and cost-effective to produce in the sense that they may be made from waste materials such as fly ash, a by-product of coal combustion. Other studies have also investigated the effect of using waste oyster shells as a partial replacement of the raw material to further decrease the costs of producing geopolymers, as well as to potentially improve their properties [2].

Because of these reasons, geopolymers are currently most known for being more environmentally-friendly alternatives to Ordinary Portland Cement. Hence, this study explores a different potential application of geopolymers - geopolymer beads about $4-5 \mathrm{~mm}$ in diameter were developed from fly ash and waste pen shells (Baluko). Foaming agents will be added as well to increase the porosity of the beads. The porous beads will then be coated with nanosilver - when put in water, silver ions are expected to leach out and neutralize any bacteria in the water. The antimicrobial properties of the nanosilver coated beads were investigated through testing against $E$. coli in water.

\section{Materials and methods}

\subsection{Materials and reagents}

Fly Ash obtained from a coal-fired power plant in Central Luzon and waste Baluko shells collected from Sorsogon, Bicol were used as the raw materials for the geopolymer beads, while $12 \mathrm{M} \mathrm{NaOH}$ and water glass solution (WGS) $\left(\mathrm{SiO}_{2} / \mathrm{Na}_{2} \mathrm{O}=2.4\right)$ formed the alkali activator. Concentrated $\mathrm{H}_{2} \mathrm{O}_{2}(50 \%)$ and Sodium Dodecyl Sulfate (SDS) were the foaming agents used. Polyethylene Glycol (PEG-600) was used as the suspension medium to produce the geopolymer beads. The nanosilver coating on the geopolymer was from either $0.1 \mathrm{M}$ or $0.5 \mathrm{M} \mathrm{AgNO}_{3}$ solution, reduced by $1 \mathrm{M} \mathrm{NaBH}_{4}$.

\subsection{Experiments}

\subsubsection{Pre-treatment of raw materials}

The fly ash for this study was used as is, while the Baluko shells were crushed, calcined at $700^{\circ} \mathrm{C}$ for two hours, ground with a mortar and pestle, and then finally sieved to mesh no. 200 (75 microns).

* Corresponding author: kimmie_delacerna@dlsu.edu.ph 


\subsubsection{Development of the geopolymer beads}

The geopolymer beads were produced through a method called suspension solidification - the geopolymer paste consisting of fly ash, calcined Baluko shells, the alkali activator, $1.5 \%$ SDS, distilled water and varying amounts of $\mathrm{H}_{2} \mathrm{O}_{2}$ (according to Table 2) were first loaded onto a needle-less syringe [3]. Table 1 summarizes the mix proportions of the geopolymer pastes made.

Table 1. Mix Proportion of the Geopolymer

\begin{tabular}{lc}
\hline Component & Amount \\
\hline $\mathrm{FA}$ & $74.67 \mathrm{~g}$ \\
$\mathrm{BS}$ & $18.67 \mathrm{~g}$ \\
$\mathrm{NaOH}$ & $7.47 \mathrm{~g}$ \\
$\mathrm{WGS}$ & $29.87 \mathrm{~g}$ \\
$1.5 \% \mathrm{SDS}$ & 4.57 \\
$\mathrm{H}_{2} \mathrm{O}$ & $2 \mathrm{~mL}$ \\
$\mathrm{H}_{2} \mathrm{O}_{2}$ & Varying \\
\hline
\end{tabular}

The paste was then injected dropwise into a PEG-600 solution temperature-maintained by a water bath, according to Fig. 1. Because of the high temperature of the PEG-600, its similar density with the geopolymer, and surface tension effects, the geopolymer eventually solidifies into suspended, spherical shapes. After twenty minutes in the PEG-600, the geopolymer beads were collected, rinsed thoroughly, then cured in a laboratory oven at $90{ }^{\circ} \mathrm{C}$ for 24 hours. Figure 2 shows the geopolymer beads.

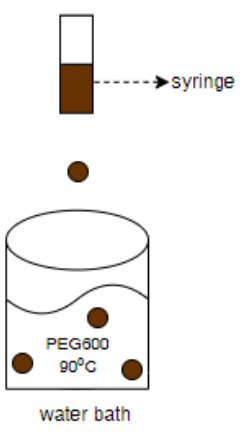

Fig. 1. Schematic Diagram of Setup

\subsubsection{Nanosilver coating application}

For each sample, twenty (20) of the dried and cured beads were introduced into $20 \mathrm{~mL}$ of different concentrations of AgNO3 solution, as shown in Table 2. After two hours, the AgNO3 was removed, and another $20 \mathrm{~mL}$ was added at the same concentration for two hours. This fixed silver ions $(\mathrm{Ag}+)$ onto the geopolymer surface. The excess AgNO3 was again removed, and $20 \mathrm{~mL}$ of $1 \mathrm{M} \mathrm{NaBH} 4$, a strong reducing agent, was added. This step rapidly reduces the $\mathrm{Ag}+$ on the geopolymer into nanosilver particles, forming the final nanosilver coated geopolymer beads (AgGP).

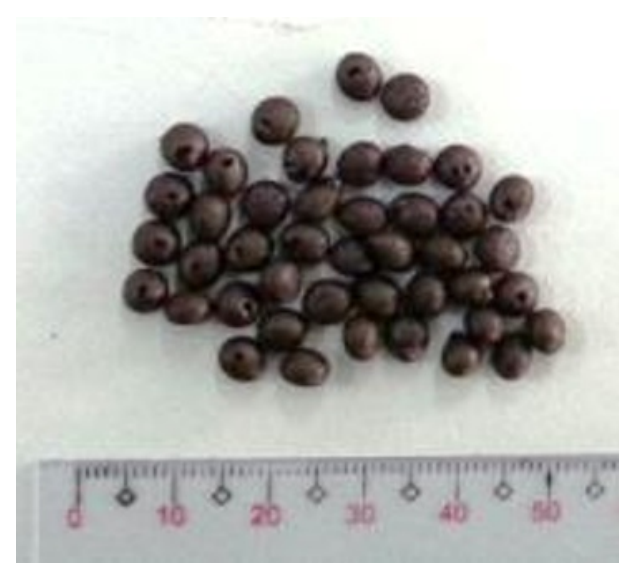

Fig. 2. Geopolymer Beads

Table 2. $\mathrm{H}_{2} \mathrm{O}_{2}$ Dosage and $\mathrm{AgNO}_{3}$ Concentrations of the Samples

\begin{tabular}{ccc}
\hline Sample & $\begin{array}{c}\mathrm{H}_{2} \mathrm{O}_{2} \text { Dosage } \\
(\boldsymbol{\%})\end{array}$ & $\begin{array}{c}\text { AgNO3 } \\
\text { Conc. }(\mathbf{M})\end{array}$ \\
\hline A & 0.15 & 0.1 \\
B & 0.15 & 0.5 \\
C & 0.35 & 0.1 \\
D & 0.35 & 0.5 \\
\hline
\end{tabular}

\subsubsection{Silver loading determination}

An acid digestion technique was used to determine the amount of nanosilver on the AgGP. About $0.6 \mathrm{~g}$ of the finely crushed $\mathrm{AgGP}$ was placed in a glass beaker. Then, $20 \mathrm{~mL}$ of concentrated $\mathrm{HNO}_{3}$ was added; this was swirled by hand and left uncovered for 48 hours under a fume hood. After the 48 hours, the solution was heated until boiling, cooled down, then finally diluted to $50 \mathrm{~mL}$ with distilled water. The liquid was tested for its silver content via Inductively Coupled Plasma-Optical Emission Spectroscopy (ICP-OES). This was done for all four samples.

\subsubsection{Antimicrobial testing}

An E. coli suspension (ECS) approximately $1 \times 10^{5}$ $\mathrm{CFU} / \mathrm{mL}$ was prepared about 24 hours prior to the experiment. Then, $30 \mathrm{~mL}$ of the ECS was added to four vials, each containing twenty (20) of the AgGP for each of the four samples. The vials were shaken in an orbital shaker at $300 \mathrm{rpm}$ for 30 minutes before adding $2 \mathrm{~mL}$ of a $5.0 \%$ wt solution of sodium thiosulfate. The sodium thiosulfate immediately stops further antimicrobial activity of the silver ions released, making sure the contact time was set at exactly 30 minutes.

Then, $1 \mathrm{~mL}$ of the ECS after treatment was extracted and serially diluted with $0.1 \%$ peptone water 3 times $\left(10^{-}\right.$ $\left.1,10^{-2}, 10^{-3}\right)$. Exactly $1 \mathrm{~mL}$ of each dilution was plate counted with Nutrient Agar as the medium. Incubation was at $37^{\circ} \mathrm{C}$ for 24 hours. This procedure was also done for a control sample using the uncoated beads. 


\section{Results and discussion}

\subsection{Surface morphology}

Figs. 2 and 3 below show low-magnification SEM images of the uncoated geopolymer beads at $0.15 \% \mathrm{H}_{2} \mathrm{O}_{2}$ and $0.35 \% \mathrm{H}_{2} \mathrm{O}_{2}$. It is evident that Fig. 2, with lower $\mathrm{H}_{2} \mathrm{O}_{2}$ dosage, has less open pores on the surface.

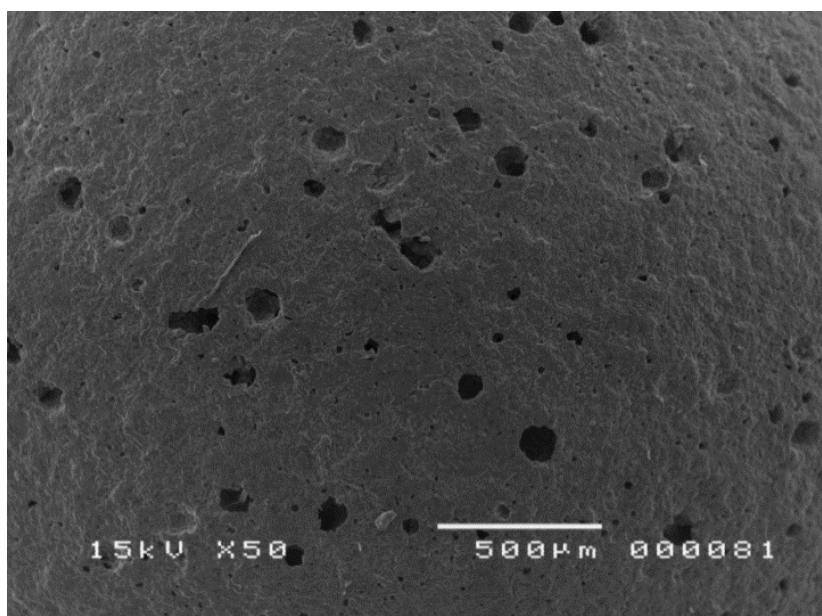

Fig. 2. Geopolymer at $0.15 \% \mathrm{H}_{2} \mathrm{O}_{2}$ Dosage, $50 \mathrm{x}$

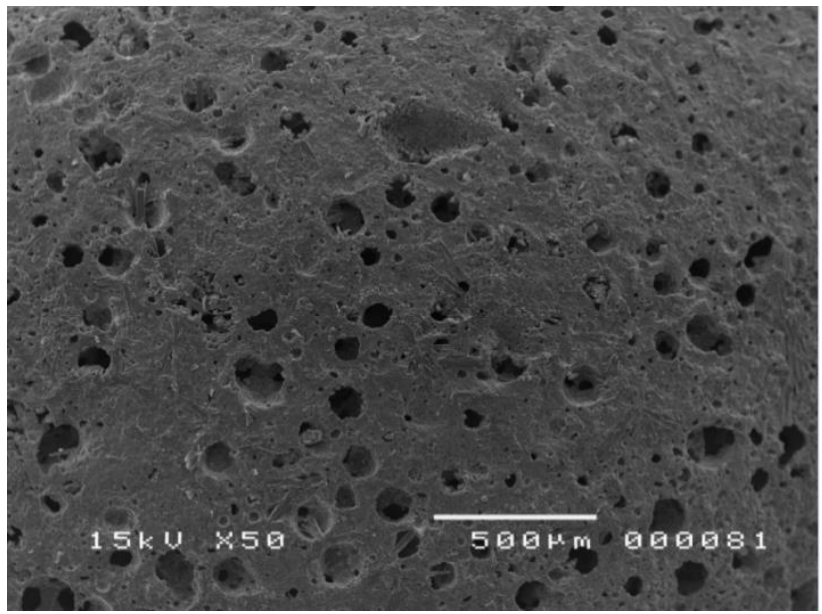

Fig 3. Geopolymer at $0.35 \% \mathrm{H}_{2} \mathrm{O}_{2}$ Dosage, $50 \mathrm{x}$

Fig. 4 shows the uncoated geopolymer at a higher magnification, and Table 3 shows the elemental analysis of the two points in the image. As expected, the geopolymer surface has high amounts of $\mathrm{O}, \mathrm{Si}$, and $\mathrm{Al}$; these are from the geopolymer framework itself, consisting of tetrahedrally linked $\mathrm{Si}$ and $\mathrm{Al}$ oxides sharing the $\mathrm{O}$ atom. Significant amountsof $\mathrm{Fe}$ are also present; this is attributed to the high amounts of Fe in the fly ash itself [4]. On the other hand, the high $\mathrm{C}$ on the surface is possibly due to carbonation of the geopolymer over time; this occurs when $\mathrm{CO}_{2}$ from the atmosphere diffuses into the geopolymer and reacts with the pore water, forming $\mathrm{H}_{2} \mathrm{CO}_{3}$, which then attacks the $\mathrm{Ca}$-containing phases in the geopolymer to form $\mathrm{CaCO}_{3}$ [5].

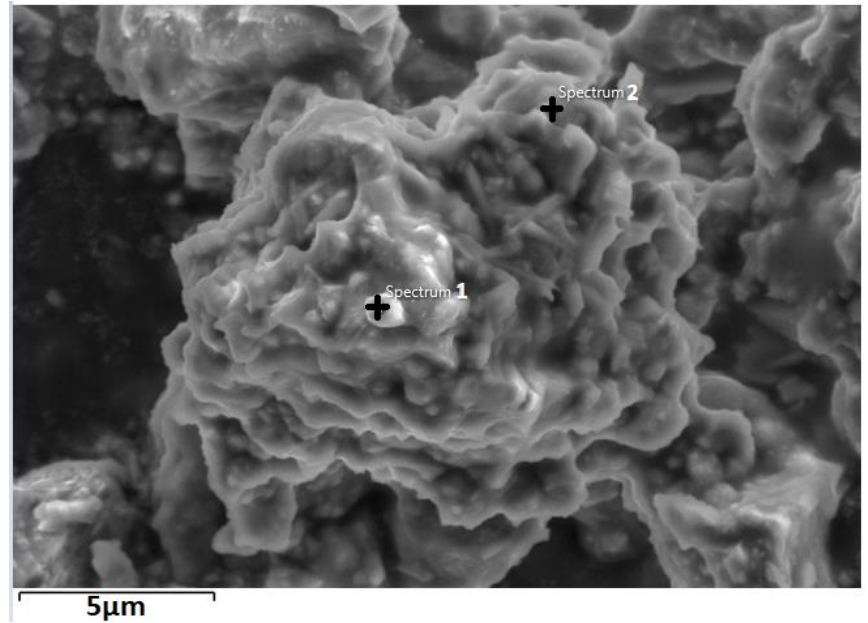

Fig. 4. SEM-EDX of Geopolymer, 10,000x

Fig. 5 and 6 show the AgGP using low and high concentration of $\mathrm{AgNO}_{3}$, respectively. Very different microstructures are evident from the two images. Comparing with Fig. 5, it seems that at higher $\mathrm{AgNO}_{3}$ concentration, more agglomeration of the nanosilver occurs.

Table 3. EDX Analysis of the Uncoated Geopolymer

\begin{tabular}{ccc}
\hline & Spectrum 1 & Spectrum 2 \\
\hline Element & \multicolumn{2}{c}{ Weight \% } \\
\hline $\mathrm{O}$ & 33.4 & 42.7 \\
$\mathrm{Fe}$ & 28.3 & 6.9 \\
$\mathrm{C}$ & 14.5 & 19.2 \\
$\mathrm{Mg}$ & 8.9 & 1.7 \\
$\mathrm{Ca}$ & 2.1 & 1.4 \\
$\mathrm{Si}$ & 5.3 & 15.2 \\
$\mathrm{Al}$ & 5.4 & 8.8 \\
$\mathrm{Na}$ & 2.2 & 2.8 \\
\hline
\end{tabular}

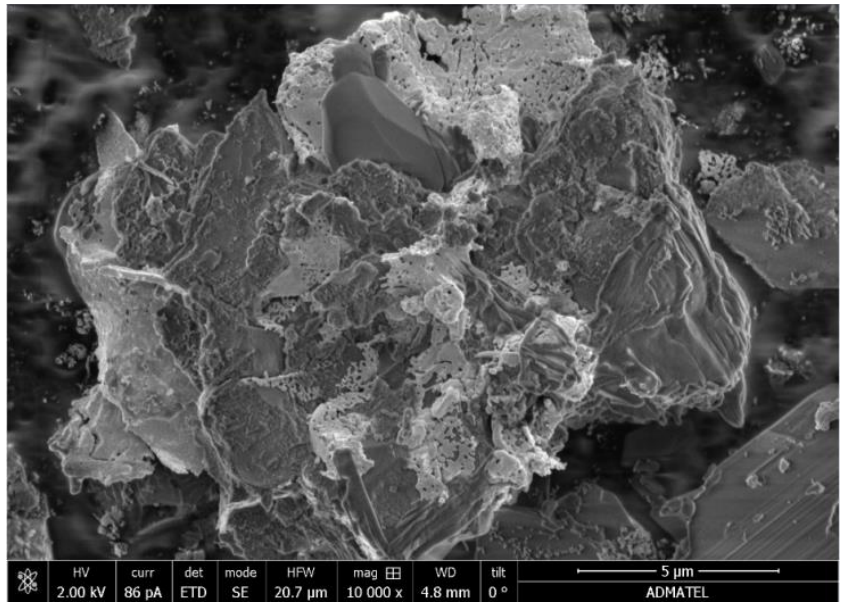

Fig. 5. AgGP Using $0.1 \mathrm{M} \mathrm{AgNO} 3,10,000 \mathrm{x}$ 


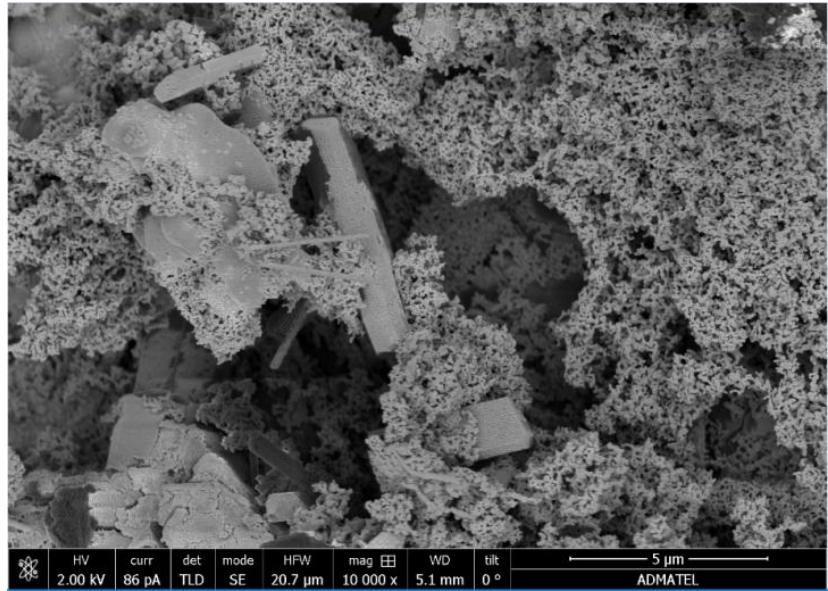

Fig. 6. AgGP Using $0.5 \mathrm{M} \mathrm{AgNO}_{3}, 10,000 \mathrm{x}$

\subsection{Antimicrobial and silver loading test}

The antimicrobial activity of the AgGP was expressed in percent bacteria reduction of $E$. coli (\%BR), according to Eq. 1 below. Table 4 shows the \%BR of each of the four samples, alongside their silver content.

$$
\% B R=\frac{\text { Initial count }- \text { final count }}{\begin{array}{c}
\text { initial count } \\
\times 100 \%
\end{array}}
$$

From Fig. 7, it may be inferred that increasing $\mathrm{H}_{2} \mathrm{O}_{2}$ dosage from $0.15 \%$ to $0.35 \%$ greatly increases nanosilver loading. This is likely due to the increase in porosity when more of the $\mathrm{H}_{2} \mathrm{O}_{2}$ is added - more porous geopolymer beads have more available space for nanosilver attachment.

It can also be seen that generally, higher silver loading results in higher \%BR. However, examining the trend on a smaller scale (such as in the left hand side of the graph), it seems that $\mathrm{AgNO}_{3}$ concentration plays a more significant role on $\% \mathrm{BR}$, with lower concentrations leading to higher \%BR. This may be because at higher $\mathrm{AgNO}_{3}$ concentrations, agglomeration of the nanoparticles predominates, producing larger nanosilver particles. Theoretically, this decreases antimicrobial activity, as the rate of release of silver ions is slowed [6] At high enough silver loading (such as on the right hand side of the graph), it is possible that the sheer quantity of nanosilver available ensures high \%BR, regardless of $\mathrm{AgNO}_{3}$ concentration used. However, for adequately porous geopolymer beads, low concentration of $\mathrm{AgNO}_{3}$ seems to be adequate to give high $\% \mathrm{BR}$.

Table 4. Silver Loading and $\% \mathrm{BR}$

\begin{tabular}{|c|c|c|}
\hline Sample & Silver (mg Ag/g) & \%BR (\%) \\
\hline A & 39.14 & 98.06 \\
\hline B & 57.89 & 77.60 \\
\hline C & 129.48 & 99.96 \\
\hline D & 237.60 & 98.97 \\
\hline Control & 0.05 & 43.53 \\
\hline
\end{tabular}

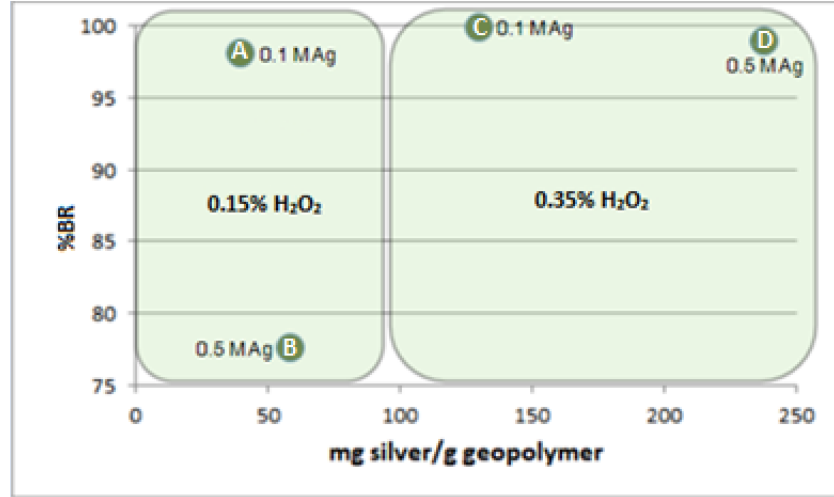

Fig. 7. \%BR vs. Nanosilver Loading

\section{Conclusion}

Nanosilver-coated geopolymer beads (AgGP) were successfully made using fly ash and calcined Baluko shells (pen shells). The AgGP had positive antimicrobial properties and produced \%BR as high as $99.96 \%$ or 3-log reduction starting from an $E$. coli suspension at $10^{5} \mathrm{CFU} / \mathrm{mL}$. Increasing $\mathrm{H}_{2} \mathrm{O}_{2}$ dosage and lowering $\mathrm{AgNO}_{3}$ concentration generally increases \%BR. This is attributed to an increase in open porosity and a decrease in nanosilver size formed, respectively. Higher silver loading is achieved at increased $\mathrm{H}_{2} \mathrm{O}_{2}$ dosage and more concentrated $\mathrm{AgNO}_{3}$.

Future studies could look into analyzing the particle size of the nanosilver at different process conditions, perhaps using techniques such as Transmission Electron Microscope (TEM), to confirm the theories presented in this paper.

This research was financially supported by the Department of Science and Technology (DOST), through their Engineering Research and Development for Technology (ERDT) scholarship program and their ADMATEL-EPDC grant.

\section{References}

[1] Ryu, G. S. et al (2013). The mechanical prop erties of fly ash-based geopolymer concrete wi th alkaline activators. Construction and Buildin g Materials, 47, 409-418.

[2] Djobo, Y. J. N. et al (2016). Partial replacem ent of volcanic ash by bauxite and calcined $o$ yster shell in the synthesis of volcanic ash-bas ed geopolymers. Construction and Building $\mathrm{Ma}$ terials, 113, 673-681.

[3] Tang, Q. et al (2015). Preparation of porous Ptype zeolite spheres with suspension solidification method. Materials Letters, 161, 558-560.

[4] Malenab, R., Ngo, J., \& Promentilla, M. (201 7). Chemical treatment of waste Abaca for nat ural fiber-reinforced geopolymer composite. Ma terials, 10(6), 579. doi:10.3390/ma10060579

[5] Bernal, S. A., et al (2010). Effect of silicate modulus and metakaolin incorporation on the $\mathrm{c}$ 
arbonation of alkali silicate-activated slags. Ce ment and Concrete Research, 40(6), 898-907. doi:10.1016/j.cemconres.2010.02.003

[6] Zhang, X., \& Shi, B. (2015). Preparation of a nanosilver composite plant medium with antimi crobial capability through a nontoxic method.

Nanomaterials and Nanotechnology, 5, 21. doi: $10.5772 / 60913$ 